\title{
REPRESENTAÇÕES SOCIAIS DA VIOLÊNCIA EM PROFESSORES DA ESCOLA PÚBLICA
}

\author{
Alexandre da Silva de Paula \\ Doutorando em Psicologia pela USP/FFCPRP. Prof. no Centro Universitário de Votuporanga
}

Sérgio Kodato

Doutor em Psicologia Escolar e Desenvolvimento Humano pela USP/SP. Prof. Dr. na USP/FFCLRP

Francielle Xavier Dias

Mestranda em Psicologia pela USP/FFCRP

\begin{abstract}
Resumo
Esta pesquisa, de abordagem qualitativa, foi realizada em uma escola pública, localizada na periferia de uma cidade de médio porte, do interior do Estado de São Paulo. Referenciando-se no método de análise das Representações Sociais, teve como objetivo investigar as concepções e as significações de violência nas escolas, produzidas por professores do Ensino Médio e Fundamental. Os dados foram coletados por meio de entrevistas semidirigidas em profundidade, com oito participantes escolhidos pelos critérios de disponibilidade e variabilidade do conjunto. As entrevistas foram gravadas, e o material transcrito foi organizado em categorias temáticas, segundo o procedimento da análise de conteúdo. As interpretações e justificativas para os episódios de violência baseiam-se em concepções pré-científicas e constituem um discurso desprovido de autocrítica, caracterizado pela impotência e por um sentido fatalista de futuro, dificultando o enfrentamento e a prevenção.

Palavras-chave: violência escolar; educação pública; representação social.
\end{abstract}

\section{SOCIAL REPRESENTATIONS OF VIOLENCE IN TEACHERS OF PUBLIC SCHOOL}

\begin{abstract}
This research, in qualitative approach, was conducted in public school situated in the periphery of a medium town in São Paulo State. The study was referenced in the method of analysis of the Social Representations and aimed to investigate the conceptions and significations of the violence at schools, produced by teachers of the elementary and high school. The data were collected through semi-structured interviews in-depth with eight participants chosen by the criteria of availability and variability of the group. The interviews were recorded and the transcribed material was organized in thematic categories, according to the procedure of content analysis. The interpretations and justifications for the episodes of violence were based in common sense and constitute a speech with lack of self-analysis characterized by impotence and fatalistic sense of future, making difficult confronting and prevention.

Keywords: school violence; public education; social representation.
\end{abstract}




\title{
REPRESENTACIONES SOCIALES DE LA VIOLENCIA EN LOS MAESTROS DE ESCUELA PÚBLICA
}

\begin{abstract}
Resumen
Esta investigación, de enfoque cualitativo, se llevó a cabo en una escuela pública, ubicada en la periferia de una ciudad de tamaño mediano, en el estado de São Paulo. Se utilizó como referencia el método de análisis de las representaciones sociales, con el objetivo de investigar los conceptos y significados de la violencia en las escuelas, producidos por los profesores de secundaria y primaria. Los datos fueron recolectados a través de entrevistas semi-estructuradas, en profundidad con ocho participantes, seleccionados por los criterios de disponibilidad y variabilidad del conjunto. Las entrevistas fueron grabadas, transcritas y se organizo el material en categorías temáticas, de acuerdo con el procedimiento de análisis de contenido. Las interpretaciones y justificaciones de los episodios de violencia se basan en concepciones pre - científicas y constituyen un discurso carente de autocrítica, que se caracteriza por la falta de poder y un sentido fatalista del futuro, por lo que es difícil el afrontamiento y la prevención.
\end{abstract}

Palabras clave: violencia escolar; la educación pública; la representación social.

\section{INTRODUÇÃO}

O processo de tomada de consciência de todos os sistemas de vigilância por câmeras, pelo ciberespaço, pelos cartões de crédito e débito, a que estamos submetidos é preocupante e indica que finalmente estamos adentrando ao mundo de George Orwell, 1984. A grande questão não é simplesmente antecipar os crimes do futuro, mas estabelecer essa modulação contínua, no presente, de todos os comportamentos, de tal forma que os indivíduos se tornem pontos localizáveis numa série de redes que se entrecruzam. Como alerta Deleuze (1992), ao afirmar que as próximas formas de controle ocorrerão em meio aberto, integrando mecanismos que rivalizam com os mais duros confinamentos, os quais fazem parte dos antigos sistemas de clausura.

Para o autor citado anteriormente, a transição do regime disciplinar para o regime do controle, evidencia a crise das instituições. No contexto educativo, o desdobramento mais nocivo do que se denomina de síndrome da violência é sua ação perversa sobre a atividade pedagógica nas escolas públicas prejudicando, especialmente, adolescentes dos setores populares que podem ser criminalizados precocemente. A violência, a agressividade e as desavenças multiplicam-se rapidamente. A cada ano, as ocorrências registradas pela ronda escolar aumentam drasticamente, e, além disso, uma série de ocorrências que poderiam ser tipificadas como crime: atentados ao patrimônio, explosão de bombas, porte de tóxicos, agressão contundente, tráfico de drogas, não são registradas e tipificadas. 
No sentido de compreender os processos de significação da violência nas escolas recorremos ao método de análise das Representações Sociais. Inaugurado por Moscovici (1978), essa perspectiva marcou um momento de ruptura com a forma individualizante de leitura dos fenômenos sociais, em psicologia social, introduzindo a abordagem sociológica, na tentativa de entendimento das relações entre indivíduo e sociedade. A violência nas escolas é geralmente interpretada como decorrente da falta de ética e cidadania dos alunos, associada a uma representação do grupo familiar como incapaz e insuficiente.

Se as representações e concepções de violência do senso comum apontam para um fenômeno impiedoso e fora de controle, isso acaba por prejudicar as relações sociais de aprendizagem e conhecimento, visto que os indivíduos investem mais suas energias psíquicas e cognitivas em se defender de um suposto ataque, do que nos processos de entendimento e compreensão do fenômeno.

Arruda (2002) postula que a teoria das Representações Sociais "permitiu alargar o foco de visão da psicologia ao incluir o contexto em que se inseriam objetos e sujeitos" (p. 68). Evidenciando que o aspecto objetivo se incorpora ao subjetivo, as Representações Sociais estão "necessariamente radicadas no espaço público e nos processos através dos quais o ser humano desenvolve uma identidade, cria símbolos e se abre para a diversidade de um mundo dos outros" (Jovchelovitch, 2000, p. 65).

Carvalho e Arruda (2008) colocam que o termo "representação" é polissêmico, apresentando uma longa tradição e uso nas Ciências Sociais. Enquanto conceito, sempre foi utilizado como expressão epistêmica por diferentes correntes de pensamento, estando imerso em uma teia de múltiplos significados, tornando a coexistência possível de acordo com o contexto histórico. Na dinâmica escolar, aquilo que os professores entendem por violência na escola é bem diferente do entendimento dos alunos.

É relativamente consensual, entre as diferentes perspectivas, que as representações sociais não podem ser pensadas como uma unidade estática e dicotômica, mas como um sistema dinâmico de saberes que se formam numa arquitetura triangular de inter-relações sujeito-outro-mundo (Jovchelovitch, 2004). Nesse sentido, postula-se que as representações sociais constituem saberes compartilhados, os quais orientam atitudes e comportamentos num 
ambiente consensual. Expressam como os homens conhecem a realidade em sua existência cotidiana, "a vida não teórica ou pré-teórica, mas o conhecimento que constitui o tecido de significados sem o qual nenhuma sociedade poderia existir" (Berger \& Luckmann, 1985, p. 30).

Esta pesquisa buscou investigar as representações sociais da violência construídas por professores de uma escola pública de periferia, localizada no interior do Estado de São Paulo. A análise das falas visou, por meio de uma interpretação compreensiva, a revelar os saberes vinculados à experiência da violência na escola e os operadores sociais construídos para fazer frente a ela. 0 desafio de realizar uma pesquisa sobre a violência e suas representações sociais, em uma escola pública, implica empenhar-se por uma análise crítica que considere a crise e a transição que atingem as instituições modernas, no sentido de sua legitimidade. Atualmente, multiplica-se uma série de acontecimentos intempestivos, atos individuais e coletivos que incitam e banalizam a violência nas instituições e no espaço público.

O incremento da violência nas instituições sociais fortalece o sentimento de insegurança, agravando a crise e deixando em suspense o processo pedagógico no imaginário escolar. Os indivíduos já não pensam em formas de como o mal pode ser afastado, "as pessoas ocupam-se com estratégias de sobrevivência, medidas destinadas a prolongar suas próprias vidas. Estratégias que refletem a crescente desesperança em modificar a sociedade" (Lasch, 1986, p. 24).

Em termos conceituais, segundo Costa (1986, p.32), a violência é o emprego desejado da agressividade com fins destrutivos, "quando uma ação agressiva é pura expressão do instinto, ou quando não exprime um desejo de destruição, não é traduzida nem pelo sujeito, nem pelo agente, nem pelo observador como ação violenta". Trata-se de uma palavra cuja significação implica referências éticas, culturais e políticas.

Arendt (1994) postula que nem a violência nem o poder são fenômenos naturais ou manifestações de um processo vital, pois pertencem ao setor político das ações humanas. A violência ganha expressão quando um indivíduo se sente incapaz de exercer o poder por meio do respeito. Sendo assim, a impotência implica em violência, um fato determinante para indivíduos com vigor natural, moral ou físico e sem capacidade de mediação e negociação.

Apesar da diversidade semântica, teórica e metodológica que limita uma linguagem comum na definição do objeto, a comunidade científica acompanha a 
propagação de linhas de pesquisa, seminários, congressos e publicações sobre o tema. Abramovay (2005) afirma que o caráter multifacetado do fenômeno implica desafios em sua delimitação. É fato que a violência nas escolas está ancorada na violência social: como sinônimo de agressão física ou verbal; delito ou crime; transgressão à ordem; discriminação, humilhação entre pares ou destruição do equipamento público.

As formas atuais de sociabilidade atravessam um processo paradoxal onde ocorrem, simultaneamente, relações sociais de cooperação e competição acirrada. Há um novo fator nos processos de socialização, a violência, "na qual se dá a afirmação de poderes legitimados por uma determinada norma social: a violência configura-se como um dispositivo de controle, aberto e contínuo" (Santos, 2001, p. 107). Em decorrência da imprecisão do conceito, BonaféSchmitt (1997) alerta sobre a visão inflacionista da violência escolar. Muitos estudos reúnem agressão física e verbal, extorsão, vandalismo, humilhação, infração e subversão da ordem institucional sobre a égide de um único problema. São necessários precaução e cuidado na classificação, para evitar distorções ou exageros.

Montoya (2002) assegura que não se trata de postular uma concepção "exclusivamente fenomenológica e subjetivista, mas sim de uma tentativa de agrupar os atos qualificados como violentos pelos próprios atores segundo categorias sociais e posturas institucionais" (p. 119). Entende-se que os significados atribuídos ao fenômeno: violência nas escolas indicam diferenças ideológicas e pedagógicas que circulam no espaço escolar, marcadas pela crise da formação social e econômica. Nesse embate de diferenças, cujo palco principal é a sala de aula, estratégias pautadas na ótica criminal surgem como alternativa para coibir os "comportamentos delinquentes" dos alunos.

Além disso, ocorre uma preocupação com índices quantitativos, com salas e com alunos matriculados. As consequências desse modo de gestão educacional englobam: decadência na qualidade do ensino, desvalorização salarial, inadequação e desorganização do espaço pedagógico frente às demandas do contingente de alunos, dentre outros fatores. Por outro lado, as características da conjuntura econômica mundial não garantem que a escolarização seja um sinônimo de acesso ao mercado de trabalho. Muitos alunos são céticos quanto às possibilidades de melhorar as condições de vida frequentando uma escola 
pública. E de fato, a escola tem sido incapaz de oferecer uma formação dinâmica e atual frente à sociedade globalizada.

Essa situação crítica pode ser testemunhada e vivida através do acompanhamento do trabalho numa Diretoria Regional de Ensino e em escolas associadas. A partir do contato diário com diretores, supervisores de ensino e professores, um fato complexo e intrigante chamou atenção: uma escola de inauguração recente, com menos de dois anos, apresentava os mais graves incidentes em termos de violência e indisciplina, principalmente, depredação e vandalismo.

A escola investigada foi objeto de estigma por alunos, comunidade e alguns professores, tendo como referência o presídio Carandiru. Será que a metáfora da escola como cárcere indica a sensação de muitos alunos, de se sentirem "presos" na escola e estarem desenvolvendo atividades sem sentido ou de pouco sentido? Como os professores percebem e representam essa forma simbólica de violência? Será que se trata de um tipo de exagero na percepção dos fatos, o que implica ancorar a escola numa esfera prisional e criminosa?

\section{MÉTODO}

Trata-se de um estudo qualitativo embasado na Teoria das Representações Sociais. A pesquisa qualitativa possibilita às ciências humanas e sociais resgatar os determinantes subjetivos, na relação entre pesquisador e participante. $O$ material primordial da investigação qualitativa é a palavra, sendo sua pretensão compreender, em níveis aprofundados, valores, práticas, lógicas de ação, crenças, hábitos, atitudes e normas culturais que asseguram aos membros de um grupo ou sociedade a atuação no seu cotidiano (Minayo, 1999).

Participantes e coleta de informações

Os dados foram obtidos por meio de entrevistas abertas, em profundidade, com oito professores que atuam no Ensino Fundamental. O conjunto de sujeitos da investigação foi composto pela escolha aleatória dos professores, buscando-se o princípio da multiplicação de pontos de vista sobre o fenômeno. A quantidade de entrevistas realizadas seguiu o critério de saturação dos dados no material empírico, ou seja, na medida em que os dados coletados foram se tornando recorrentes e suficientes para alcançar os objetivos da pesquisa.

O uso de entrevistas é fundamental quando se visa a "mapear práticas, crenças, valores e sistemas classificatórios de universos sociais específicos, em 
que os conflitos e contradições não estejam claramente explicitados" (Duarte, 2004, p. 220). Entende-se que as entrevistas não se reduzem a uma troca de perguntas e respostas previamente preparadas, mas a um instrumento dialógico de interação.

Um roteiro de perguntas foi elaborado a partir de tópicos que contemplaram duas dimensões, a saber, uma dimensão pessoal (história de vida dos participantes) e uma dimensão pedagógica e institucional (discurso sobre educação e violência). Os pesquisadores foram apresentados aos professores a partir de uma reunião na Hora de Trabalho Pedagógico Coletivo (HTPC), com a presença da diretora e vice-diretora. No início das entrevistas, os pesquisadores apontaram os aspectos éticos da pesquisa, informando aos participantes sobre os objetivos, o sigilo e a possibilidade de desistência em qualquer situação de incômodo.

Instrumentos para análise dos dados

Adotou-se a referência de Minayo (1999) na análise de conteúdo que, embora se sustente na categorização das falas, propõe que o processo não se reduza à quantificação de frequências, mas sim a um aprofundamento qualitativo dos discursos. A partir da análise em categorias temáticas, visou-se a oferecer uma visão panorâmica e contextual das marcas discursivas dos entrevistados, salientando um enfoque compreensivo. As unidades de análise consistem em palavras, expressões, frases ou enunciados que se referem aos temas apropriados, em função de sua situação no conteúdo.

\section{RESULTADOS}

a) Sentidos da prática docente

Nesta categoria os entrevistados relatam algumas experiências pedagógicas no ensino público. As falas apontam conflitos na função do educador, o que remete a uma crise na identidade profissional. É possível perceber que ocorrem dificuldades com planejamento e execução das aulas. Em decorrência de tais problemas, a função do educador se confunde com a função de um membro da família do aluno. A afetividade é colocada em destaque como mediadora que permite despertar algum interesse pelo ensino. Os limites didáticos ou pedagógicos são canalizados para um problema de ordem psíquica, a suposta carência afetiva se sobrepõe às demais questões estruturais ou pontuais da educação pública. 
"O desinteresse era muito grande, de certa apatia das coisas" (P1).

"Não adianta chegar à sala de aula e achar que vai passar o que está no planejamento. No começo (...) é assim de passar o conteúdo e não me preocupei muito com a realidade deles" (P2).

"De forma afetuosa posso trazer eles pro meu lado" (P3).

"O aluno, noventa por cento, vai buscar a parte afetiva" (P6).

"A partir do momento em que eu entrava na sala de aula eu não sabia o que ia acontecer" (P8).

"O papel do professor é completar o que o aluno tem em casa, é ajudar o aluno com a parte afetiva" (P8).

b) Ética e saúde mental do professor

Nesta categoria emergem as representações dos entrevistados sobre a conduta profissional dos demais professores. São observadas recorrentes referências à falta de compromisso e pouca motivação com o trabalho. A rotina de faltas ou o uso de recursos burocráticos para se ausentar da sala de aula indicam a insatisfação, o desgaste mental e sofrimento no trabalho, num quadro de desânimo, lamentações, reclamações e pessimismo. Essas experiências vividas acarretam decepção e falta de perspectiva profissional. Quando se esgotaram os recursos pessoais disponíveis: "não há o que fazer". Nesta categoria percebe-se uma forma de violência moral com implicações éticas: qual conduta o professor deve adotar numa escola pública onde prevalece o desânimo coletivo?

"A gente vê na sala dos professores, reclamam de tudo, nada está bom" (P1).

"Eu não sei mais se o professor tem que fazer" (P1).

"Um professor está desanimado, não tem ânimo" (P2).

"Às vezes a mesma porcaria de professor que tem aqui, tem lá na escola do centro, e se bobear até pior" (P2).

"Você começa a questionar se adianta ter uma moral, uma ética que te leva aonde?" (P2).

"É professor que falta demais, eu nunca vi uma coisa desta. Eu vejo a loucura... o professor falta e não está nem aí" (P6).

"Ontem teve reunião, mas a gente só ficou conversando" (P8). 


\section{c) Vínculo professor-aluno}

Nesta categoria as marcas discursivas apontam para uma degradação do vínculo professor-aluno, as relações interpessoais se caracterizam pela indiferença, rivalidade e crueldade. A provável psicopatologia desse vínculo reforça a disputa desigual pelo poder e autoridade, onde o professor é escolhido e se coloca como vítima. Essa categoria permite compreender as dificuldades no manejo e domínio dos processos de mediação e controle disciplinar, por parte dos docentes. A escassez de mediadores didáticos nas situações problemáticas pode implicar num quadro recorrente de banalização e aceitação dos incidentes que passam a ser representados como inevitáveis, ou seja, implicando numa noção ou representação fatalista de violência na escola.

"Esse enfrentamento entre alunos e professor hoje é praticamente diário" (P1).

"Ali o professor era qualquer, era tido como um coitado" (P7).

"Eu presencio é aluno que faz de tudo para irritar o professor, que não deixam dar aula" (P6).

"A professora chegou a largar a sala de aula porque não aguentou o menino que cutucava ela com palavras e com gestos" (P8).

"É um embate com o professor, ele quer mostrar que ele pode fazer o que ele quiser e ninguém pode fazer nada" (P8).

d) Estigma e violência simbólica à instituição

Nesta categoria emergem falas sobre o preconceito e estigma da comunidade escolar em relação à instituição. A escola no imaginário da comunidade local está associada a "uma praça de guerra". A comparação entre a escola e o presídio "Carandiru" expõe uma representação coletiva alarmista, a rejeição dessa escola e a autodepreciação. Para os entrevistados, há um exagero no discurso coletivo dos demais professores, alunos e pais quando se referem à escola caracterizando-a como uma instituição perigosa.

"As outras escolas até veem a escola assim como Carandiru e às vezes até apontam, nossa você é aluno do Carandiru!" (P1).

"Quando chama alguém de preso ele fez algum crime, fez alguma coisa, se você estuda em uma escola que tem o nome de uma prisão é quase de uma rejeição assim né?" (P1).

"Parecia que era um caldeirão que estava a ponto a explodir" (P2). 
"Existem relatos assim: Nossa! Você dá aula lá no Carandiru, não é perigoso?" (P4).

"De manhã começa o fogo baixo, de tarde está fogo alto e de noite já está em chamas" (P7).

\section{e) Conceitos e ancoragem da violência}

Nesta categoria emergem as interpretações sobre os incidentes que ocorriam no contexto escolar e seu entorno. Os participantes afirmam que não há uma "violência perigosa", uma vez que a representação é amparada num parâmetro penal e delituoso. Os discursos não corroboram a noção de que a escola era um lugar perigoso e cercado de ameaças. A forma mais frequente de violência está no "embate entre professor e aluno", uma forma de "violência moral" que prejudica as relações interpessoais na escola. Além disso, os entrevistados afirmam que a violência física "é uma palavra um pouco forte" para os conflitos entre alunos e professores. As representações das causas desses conflitos transitam entre a indisciplina ou a ausência de punições.

"Há violência verbal, aqueles confrontamentos (sic) que machuca até mais que um tapa, do que uma violência física" (P1).

"Sei lá eu vejo desta forma, não sei nem se é realmente, assim... uma violência!" (P2).

"É indisciplina que teria que ser desconstruído com regras" (P2).

"Todo mundo (...) acha que vai encontrar uma praça de guerra. E não é isso" (P2).

"Na verdade não era isso [violência], eles queriam chamar atenção para eles" (P3).

"Tem uma violência, mas não é tão perigosa" (P5).

"Eu acho que é um exagero, tem violência, mas não é tudo isso" (P8).

f) Fatores constitutivos na relação escola-comunidade

Nesta categoria emergem as interpretações dos professores sobre a participação dos pais na escola. Entende-se que a própria comunidade criminaliza os alunos, usando termos como "delinquentes", "malandros", "manos". A noção de que "santo de casa não faz milagre" é significativa, tendo relação com "o trabalho de destruição" e o estigma da escola como unidade prisional. Na opinião dos entrevistados, os familiares contribuem com a reprodução de estereótipos e preconceitos em relação à escola e aos alunos considerados "problemáticos". 
"A comunidade é assim... Eles não conseguem admitir a importância da escola" (P2).

"Tem um pessoal que não gosta da escola né? O pessoal do próprio bairro" (P3).

"Uma mãe perguntou quem era aqueles 'manos' na porta da escola" (P4).

"A comunidade (...). Ela faz um trabalho de destruição" (P4).

"Figuraram um nome para escola, até desagradável. A própria população, os alunos" (P7).

g) Resignação e fatalismo

Nesta categoria os problemas da escola são colocados como inevitáveis. As falas não indicam possibilidades de mudança, transformação ou negociação. $O$ discurso é polissêmico e envereda para distintas justificativas: a escola e a educação pública não têm qualidade; a direção é passiva; os problemas se acumulam numa "bola de neve" e ninguém faz nada; o professor é "retrógrado" e não desperta interesse pelo ensino. É diante dessa teia crítica e pessimista que emergem a noção fatalista, os sentimentos de impotência e a resignação.

"É um fato consumado já é o penúltimo país em educação, tá?" (P2).

"Não há quem mude eles [alunos] não estão nem aí" (P2).

"É assim, como uma bola de neve (...) ninguém resolvia, todo mundo ficava parado" (P4).

"O professor não interfere no pensamento do aluno". (P4).

"Na escola pública não tem cobrança, diálogo nenhum" (P6).

"A professora levava o caso para direção, não acontecia nada" (P7).

h) Naturalização e pedagogia do encaminhamento

Nesta categoria as falas atribuem as origens dos problemas a fatores extrainstitucionais. O discurso é desprovido de autocrítica, e a culpa pelo fracasso escolar é direcionada para o Estado, que não propicia condições de trabalho; para as famílias "perturbadas" que prejudicam o desenvolvimento dos alunos; para o aluno que reage ao "distúrbio emocional" "naturalmente" com agressão. Uma vez que o problema é tratado no âmbito da psicopatologia, os professores encaminham a responsabilidade para outras esferas, desse modo, 0 aluno necessita de intervenção psicológica e não pedagógica.

"A tendência natural dele é de agressão, agressão verbal, agressão às vezes física" (P1). 
"O Estado te obriga ser descompromissado. Ele faz ingressar no inferno" (P2).

"A família não cumpre mais seu papel" (P2).

"O aluno tinha noção de decência, hoje eles não têm noção" (P2).

"A gente tem que botar a culpa em alguém, bota no Governo" (P3).

"O lado psicológico está bem forte, sei lá. Eu acho que é um distúrbio" (P4).

"Onde ele vai suprir esta carência? Vai agredir as pessoas" (P8).

\section{DISCUSSÃO}

Debarbieux (2002) afirma que não há um conhecimento total sobre o fenômeno da violência nas escolas, uma vez que "ele só pode ser representado de formas parciais, e devemos ou aceitá-las como tal ou nos permitir cair na fantasia da onisciência" (p. 65). Neste estudo, o universo consensual da violência na escola aponta para a esfera da sociabilidade, das relações interpessoais entre professor-aluno. A forma de violência mais frequente ancora-se na agressão verbal que ocorre nas configurações desiguais de força, poder e autoridade. $O$ professor é uma figura de autoridade cuja presença é, muitas vezes, indiferente, que precisa apelar para a afetividade do aluno porque o conhecimento e aprendizagem não despertam tanto interesse da maioria.

O manejo do ambiente escolar pressupõe o controle disciplinar e a manutenção de um clima amistoso, permitindo uma atmosfera saudável e propícia à aprendizagem. Contudo, nesta pesquisa, de um lado constatou-se a desordem na sala de aula, representada como um palco de embates, e de outro, o professor destituído de sua autoridade e representado como um "coitado".

A rotina de pedidos de afastamento, os atestados médicos e as faltas frequentes são efeitos do sofrimento psíquico, do desgaste na saúde mental do professor que não encontra suporte institucional para resolver os problemas advindos da organização do trabalho. Diante disso, a violência na escola é enunciada não somente em relação aos alunos, mas, coloca-se também em questão a capacidade da instituição e de seus agentes suportarem e manejarem as situações conflituosas (Charlot, 2002).

A ideia de abandono da profissão deve ser entendida não apenas como renúncia ou desistência, mas sim como o desfecho de um longo processo de insatisfações que significam o cancelamento das obrigações assumidas com a educação pública (Lapo \& Bueno, 2002). Trata-se de pensar o sistema educativo 
no contexto das sociedades tardias, onde a ética é "minimalista, isto é, reduzida à retórica, de forma a se aceitar que as pessoas podem agir da forma que quiserem desde que bem justificadas" (Sawaia, 1995, p.51).

A inexorável violência social é o saber prévio que ancora as representações da violência nas escolas. Nas significações dos atores, se crimes como roubos, furtos, vandalismo, homicídios ou tráfico de entorpecentes não ocorrem, os acontecimentos não são percebidos como violentos. Dessa forma, entende-se que o boletim de ocorrência policial é a prova material da violência na escola. Contudo, as explicações sobre as causas dessa violência encontram suporte num discurso formatado, impessoal, o que pode ser considerado um indicador do distanciamento e da culpabilização do outro: a crise das famílias, a burocracia do Estado, a progressão continuada ou a carência afetiva e a inoperância do aluno.

Segundo Joffe (1998), as crises criam a possibilidade de uma experiência transformadora num contexto caótico e precário. Por ameaçar a ordem e a harmonia subjetiva, as mudanças e a instabilidade podem ser perigosas e potencialmente poluidoras, refletindo uma cisão, um "nós" correto e um "eles" desordenado. A representação social da escola, objetivada num "espaço ruim", "caldeirão fervendo" ou "presídio", implica uma dupla associação de ideias: ou na sua destruição ou na criminalização dessa instituição.

Para Goffman (1982), a questão do estigma surge apenas onde há alguma expectativa. Aqueles que têm relações com ele não conseguem lhe dar o respeito e consideração, o estigma faz referência a uma identidade social negativa. $O$ termo estigma deve ser usado em referência a um atributo profundamente depreciativo, porém, sua formação ocorre através de uma linguagem de relações e não de atributos. A comparação, entre uma escola pública e um presídio "Carandiru", expõe um discurso coletivo enviesado por uma visão alarmista e desproporcional.

Essa referência à escola como "Carandiru", em outras unidades ouvem-se falas de "cadeião", "cadeia" indicando a representação da instituição como cárcere e a sensação de "estarem presos". Não realizam nenhuma atividade pedagógica, produzem poucos sentidos existenciais, são constantemente vigiados, perseguidos por olhares desqualificadores ou punitivos, pouco sabem sobre o sentido da escola, do conhecimento e do futuro. Como aponta Deleuze (1992) o símbolo, por excelência, das instituições disciplinares, tal como a escola ou a família é a prisão. 
No que se refere aos sentidos das representações que professores produziram acerca do fenômeno da violência na instituição, podemos apreender que as falas apontam para um discurso polissêmico que envereda para distintas justificativas e conceitos. O professor, incapaz de mudar o seu presente, mantém o distanciamento em relação à rotina de conflitos. Não há tentativas de reação ou transformação, os alunos são vistos como "problemas", a educação como "uma das piores" e o próprio professor se "sente vencido". Mesmo reconhecendo as necessidades de mudanças, os professores não apontam reflexões, discussões ou sugestões para inovar ou mesmo amenizar os conflitos diários.

Há uma dimensão educativo-familiar nos discursos. A partir da incivilidade dos alunos que não aprenderam o que é certo ou errado socialmente, os professores encaminham os problemas para as famílias. Nessa visão, a crise da família é relacionada ao enfraquecimento e à instabilidade da sociedade e tem repercussões na educação. Os participantes entendem que a reposição de uma vida privada ideal seria um reduto de decência, amor e civilidade para o aluno "agressivo" e "revoltado", por esse ser carente de afeto.

Destacou-se uma dimensão psicologizante e moralista nos discursos sobre a violência. Nessa perspectiva o insucesso ou fracasso dos alunos é compreendido a partir de uma matriz individual, vinculada à noção de doença mental. Sendo assim, atribuem-se causas psicopatológicas aos comportamentos "perturbados", indisciplinados e agressivos.

Patto (1984) critica o modelo nutricional da carência psicológica para explicar as "deficiências escolares" dos alunos pobres. As supostas "deficiências psicológicas", muitas vezes, são atribuídas a um tipo de déficit semelhante à privação alimentar. "A criança privada ou carenciada teria recebido quantidades insuficientes de nutrientes do tipo necessário a um desenvolvimento psíquico adequado".

Situando a discussão no âmbito da profissão, Reger (1981) salienta o dilema da psicologia escolar enquanto uma prática voltada para o atendimento clínico individual. As críticas do autor em relação à atuação dos psicólogos como consultores em saúde mental nas escolas são relevantes. Esse modelo clínico tem sido amplamente questionado, uma vez que o comportamento do aluno é dissociado, de forma artificial, da cultura escolar.

Assim como as instituições disciplinares (família, escola, prisão, hospital, manicômio, fábrica) estão em crise, para Deleuze (1992) o papel disciplinar da 
psicologia na escola também está em meio a uma transição. Há grandes dúvidas sobre o que se faz: vive-se a contradição de ter sido formado no modelo do "setting" tradicional e ter que dar respostas mais coletivas e engajadas politicamente, utilizando-se estrategicamente de formas inovadoras que são emergentes na atualidade e que o psicólogo pouco teve em sua formação.

Enfim, a suposta escalada da violência nas escolas é uma construção coletiva que, muitas vezes, é endossada pelo discurso acadêmico onde prevalece a noção de que a crise do sistema educativo decorre de um único problema, a violência. Ao buscarmos as considerações dos professores sobre os problemas da instituição, percebemos que se trata de um discurso resignado e desprovido de autocrítica.

\section{CONSIDERAÇÕES FINAIS}

A análise das representações sociais de violência nos permitiu acessar a atividade empírica da consciência de professores, sua produção de saberes e sentidos interligados na trama do tecido social. Nas explicações sobre o fenômeno empírico, os sujeitos entendem que é um fenômeno histórico inerente à violência social e à degradação das famílias, e o professor é um ser insignificante que pouco age sobre o mundo da sala de aula e interpreta estereotipadamente a conduta dos alunos, legitimando a criminalização da pobreza e da indisciplina.

Ao tomar a atividade do sujeito social enquanto produção simbólica, a Teoria das Representações Sociais "é uma alternativa de grande plasticidade, que busca captar um fenômeno móvel, por vezes volátil, por vezes rígido, cuja complexidade reforça a dificuldade de sua captação" (Arruda, 2002, p. 138). Aborda-se o fenômeno da violência nas escolas, não apenas como produto de determinações sociais, nem como fator etiológico, na medida em que "as representações são sempre construções contextualizadas, resultados das condições em que surgem e circulam" (Spink, 1993, p. 303).

Diante disso, entendemos que as representações sociais de violência nas escolas, ancoradas em concepções de inexorabilidade, naturalização, imobilismo e pessimismo, constituem um campo conflituoso no que tange à produção de subjetividade, no sentido de implicar-se no combate à violência, através do incremento e melhora da produção pedagógica. Pois, o que está em pauta é a desconstrução de uma teia de significados negativos e depreciativos que 
sustentam o cotidiano do imaginário do medo, capaz de criar efetivamente uma realidade social paralisante e imobilista.

Considerando-se 0 conjunto de representações e práticas sociais construídas e mobilizadas em função da temática da violência, adotou-se a estratégia metodológica inspirada nas pesquisas do Observatório Europeu de Violência, dando-se ênfase a um enfoque psicossocial e simbólico da violência. Buscamos abarcar tanto as experiências dos atores educacionais (como vítimas, agentes ou testemunhas) como o imaginário sobre as violências vividas e praticadas (Abramovay, 2005).

Debarbieux (2002) ressalta que o objeto violência nas escolas não deve ser abordado como um todo indivisível, pelo contrário, é necessário multiplicar os pontos de vista que conduzem à pluralidade de representações, admitindo uma definição ampla que rege o problema. Essa orientação metodológica permitiu uma compreensão psicossocial dos fatores mediadores de comportamentos e práticas sociais cotidianas dos alunos, associados às representações sociais da violência.

Deve-se considerar que apesar do desânimo, fatalismo e falta de autocrítica de muitos professores, houve falas que indicam a presença de uma "minoria ativa", no sentido de Moscovici (2011), um grupo de docentes que por trazerem propostas diferentes de resistência e criação de novos agenciamentos coletivos enunciam o tímido e opaco poder do instituinte.

\section{REFERÊNCIAS}

Abramovay, M. (2005). Cotidiano das escolas: entre violências. Brasília: UNESCO.

Arendt, H. (1994). Sobre a violência. (A. Duarte, Trad.). Rio de Janeiro: RelumeDumará. (Original publicado em 1969)

Arruda, A. (2002). Teoria das representações sociais e teorias de gênero. Cadernos de Pesquisa da Fundação Carlos Chagas, 117, 127-147.

Berger, P., \& Luckmann, T. (1985). A construção social da realidade: tratado de sociologia do conhecimento. (F. S. Fernandes, Trad.). Petrópolis: Vozes. (Original publicado em 1966)

Bonafé-Schmitt, J. (1997). La médiation scolaire: Une technique de gestion de la violence ou un processus éducatif? In B. Charlot \& J. Emin (Eds.), Violences à I'École. État des savoirs (pp. 255-282). Paris: Armand Colin. 
Charlot, B. (2002). A violência na escola: Como os sociólogos franceses abordam essa questão. Sociologias, 3(4), 432-442.

Carvalho, J. G. S. \& Arruda, A. (2008). Teoria das representações sociais e História: Um diálogo necessário. Paidéia (Ribeirão Preto), 18, 441-456.

Costa, J. (1986). Violência e Psicanálise (2a. ed.). Rio de Janeiro: Graal.

Debarbieux, E. (2001). A violência na escola francesa: 30 anos de construção social do objeto (1967-1997). Educação e Pesquisa, 27(1), 163-193.

Debarbieux, E. (2002). Violências nas escolas: Divergências sobre palavras e um desafio político. In E. Debarbieux \& C. Blaya (Orgs.), Violência nas escolas e políticas públicas (pp. 59-87). Brasília: UNESCO.

Deleuze, G. (1992). Post-Scriptum: Sobre as sociedades de controle. In: Conversações. São Paulo: Editora 34.

Duarte, R. M (2004). Entrevistas em pesquisas qualitativas. Educar em Revista, $24,213-226$.

Goffman, E. (1982). Estigma: Notas sobre a manipulação da identidade deteriorada ( $4^{a}$ ed.). Rio de Janeiro: Zahar.

Joffe, H. (1998). Degradação, desejo e o "outro". In A. Arruda (Org.), Representando a alteridade (pp. 109-128). Rio de Janeiro: Vozes.

Jovchelovitch, S. (2000). Representações sociais e esfera pública: A construção simbólica do espaços públicos no Brasil. Petrópolis: Vozes.

Jovchelovitch, S. (2004). Psicologia social, saber, comunidade e cultura. Psicologia \& Sociedade, 16(2), 20-31.

Lapo, F. R. \& Bueno, B. O. (2002). O abandono do magistério: Vínculos e rupturas com o trabalho docente. Psicologia USP, 13(2), 243-276.

Lasch, C. (1986). O mínimo eu: Sobrevivência psíquica em tempos difíceis. (J. R. M. Filho, Trad.). São Paulo: Brasiliense.

Minayo, M. C. S. (1999). O desafio do conhecimento: Pesquisa qualitativa em saúde (5a. ed.). Rio de Janeiro: Hucitec.

Montoya, I. (2002). Violências nas escolas: Orientação e situação atual das pesquisas na França. In E. Debarbieux \& C. Blaya (Orgs.), Violências nas escolas: Dez abordagens européias (pp.103-129). Brasília: UNESCO.

Moscovici, S. (1978). A representação social da psicanálise. Rio de Janeiro: Zahar. (Original publicado em 1961)

Moscovici, S. (2011). Psicologia das minorias ativas. Rio de Janeiro: Vozes. 
Patto, M. H. S. (1984). Psicologia e ideologia: Uma introdução crítica à psicologia escolar. São Paulo: T. A. Queiroz.

Reger, R. (1981). Psicólogo escolar: Educador ou clínico? In M. H. S. Patto (Org.), Introdução à psicologia escolar (pp. 9 - 15). São Paulo: T. A. Queiroz.

Santos, J. V. T. (2001). A Violência na escola: Conflitualidade social e ações civilizatórias. Educação e Pesquisa, 27(1), 105-122.

Sawaia, B. B. (1995). Psicologia social: Aspectos epistemológicos e éticos. In S. T. M. Lane, \& B. B. Sawaia (Orgs.), Novas veredas da psicologia social (pp.45-53). São Paulo: EDUC/Brasiliense.

Spink, M. J. P. (1993). O conceito de representação social na abordagem psicossocial. Cadernos de Saúde Pública, 9(3), 300-308.

Contato: aledpaula@outlook.com, skodato@ffclrp.usp.br, franciellexdias@yahoo.com.br

Recebido em: 12/01/2014

Revisado em: 24/02/2014

Aceito em: 06/03/2014 